\title{
CORRESPONDENCE
}

\section{INFLUENCE OF THE CRANIAL NERVES ON INTRA-OCULAR PRESSURE}

\section{To the Editorial Committee of the British Journal of OPHTHALMology}

DeAR SIRS-Greaves and Perkins (1953) have recently published a paper on the influence of the third nerve upon the intra-ocular pressure. They seem to feel that their findings confirm the views of Henderson and Starling (1904) and refute the results of Schmerl and Steinberg (1949) obtained by different experimental procedures; they found, in short, that preganglionic or intracranial electric stimulation of the third nerve did not affect the intra-ocular pressure of five tested rabbits, except for some increase produced by the contraction of the extra-ocular muscles which lasted just as long as the period of stimulus (about $25 \mathrm{sec}$.). Intracranial section of the third nerve did not lower the ocular tension in one eye of the one rabbit followed up for several months.

The latter result cannot be discussed since it is based on a sample of one. The other findings might be correct for the procedure used by the authors, but they do not tend to confirm the findings of Henderson and Starling, for these authors studied the influence of the sympathetic and the fifth nerve, not of the third.

It is hoped that this note will stimulate the study of Henderson and Starling's valuable paper.

Toledo, OHIO, U.S.A.

Yours faithfully,

E. SCHMERL.

July 5, 1953.

\section{REFERENCES}

Greaves, D. P., and Perkins, E. S. (1953). British Journal of Ophthalmology, 37, 54.

Henderson, E. E., and Starling, E. H. (1904). J. Physiol., Lond., 31, 305.

Schmerl, E., and Steinberg, B. (1949). Amer. J. Ophthal., 32, 947.

\section{BOOK REVIEWS}

Diathermy Treatment of Intra-Ocular Tumours. By M. J. Melchers. 1953. Pp. 135, 43 figs, bibl. M.D. Thesis, Utrecht. (Unpublished).

This is an interesting and important monograph emanating from Professor Weve's clinic at Utrecht.

Until comparatively recent times the only accepted treatment of malignant tumours of the eye, particularly melanomata and retinoblastomata, has been early enucleation, and the extreme malignancy of these tumours is indicated by the fact that, despite this drastic therapeusis, statistics show that death from metastases or spread usually ranges from 40 to 50 per cent. Enucleation, of course, is a drastic method of treatment, almost insupportably so when the neoplasm affects an only eye or (as in retinoblastomata) is bilateral. It is to the credit of Weve to have attempted an alternative method of treatment, by initiating destruction of retinoblastomata by diathermy in 1930 and of malignant melanomata in 1934. The present monograph, while containing a lucid and interesting account of the origin, clinical appearances, pathology, and life-history of the more common intra-ocular tumours, summarizes the value of this method of treatment as practised at Utrecht. In general, surface diathermy (70 to $100 \mathrm{ma}$.) is advocated; perforating diathermy may lead to an outbreak of the tumour through the sclera (malignant melanoma, retinoblastoma) or haemorrhage (angiomatosis). 
On the basis of a series of seventeen cases it is concluded that diathermic coagulation is a satisfactory method of treating malignant melanomata provided the tumour is less than 8 disc diameters and is not situated near the optic disc. Of seven patients with a history of more than 10 years who were treated in this way, one has died of carcinoma of the prostate; of five patients treated between 1943 and 48 (5 to 10 years' history) one had died of acute rheumatism; all the patients treated since 1948 are alive. In no case was a renewal of intra-ocular growth observed. The fact that the mortality after this treatment (in this small series) is significantly less than after excision is striking, and raises questions (which cannot be answered) whether the dissemination of the break-down products of the coagulated neoplasm may perhaps inhibit metastases. Three cases of melanomata of the choroid suspected of malignancy were also treated, and no further growth resulted.

With retinoblastoma, the results were less favourable. Of sixteen patients thus treated, only two have retained an eye with reasonable visual acuity, and both of these had treatment by $x$ rays in addition. It is concluded that irradiation is the better method of therapy. On the other hand, five cases of angiomatosis of the retina responded well to diathermic coagulation; in early cases local cure can be obtained, in advanced cases, improvement.

This is a carefully executed and unbiased monograph which well repays study.

Long-Term Diabetes. By KNUD LundBaEK (Ophthalmological Section written in collaboration with V. A. JeNSEN). 1953. Pp. 197, 33 figs, 22 tables, bibl. Ejnar Munksgaard, Copenhagen. (D.Cr. 32s.).

The author describes the clinical picture of long-term diabetes and includes an analysis of the nature of long-term diabetic complications. The book contains the results of an extensive and painstaking follow-up of diabetics in a Danish urban municipality and includes a review of the relevant literature. While the general analyses and the detailed data contained in the various Tables are comprehensive, they are somewhat involved and in some cases complex. The use of unattractive terms, (i.e. "phlebopathy", "pigmentopathy", and "sanguinolent spots"), detracts from the literary standard of the book.

It is regrettable that, in the section dealing with diseases of the eye, more detailed and comprehensive descriptions are not given of the retinal changes observed by the author and the variability of the retinal picture.

The general views expressed in this publication are not controversial, but the statement that venous changes (phlebopathy) must be considered as belonging chiefly to juvenile diabetic retinopathy will not be subscribed to by many readers.

The work adds little that is new to the existing literature, but it gives an overall picture of the long term diabetic syndrome which is most probably representative of the diabetic population as a whole. The book is well printed but the few illustrations are poor.

The Objective Testing of Visual Acuity by Opticokinetic Nystagmus (Objektive Prüfung der Sehleistungen mit Hilfe der optokinetischen Augenbewegungen). By J. Онм. 1953. Pp. 181, 135 figs, bibl. Enke, Stüttgart.

This monograph, brought out as a compliment to Wagenmann on his ninetieth birthday, is a summary of Ohm's work on opticokinetic nystagmus, particularly its application to the objective testing of visual acuity. Ohm has worked on this problem for almost a quarter of a century and his many elaborate contributions to our knowledge of this and kindred subjects are well known to readers of German ophthalmological literature. It is well known (as was first recorded by Purkinje) that when successive moving objects traverse the visual field and excite attention, the eyes follow one object in a slow movement towards the periphery and then jerk back quickly when they are attracted by its successor. When the objects are vertical stripes on a rotating drum, the resolving power of the eye can be assessed by determining the lower limit of the visual angle subtended by the stripes which will excite attention. Moreover, since the response is an automatic reflex, its presence provides a test of the visual acuity in non-co-operative people, in malingerers, in 